\title{
Backward and forward masking in the perception of cutaneous stimuli
}

\author{
JEAN-MARIE COQUERY and BERNARD AMBLARD \\ Centre National de la Recherche Scientifique, Département de Psychophysiologie Générale \\ 31, chemin Joseph Aiguier, Marseille, France
}

\begin{abstract}
Masking of the perception of an electrical test stimulus by a mechanical shock was studied in six Ss. Forward and backward masking were observed in all $\mathrm{Ss}$, the former being of longer duration. Duration of the masking effects is inversely related to the intensity of the test stimulus. Masking effects may be preceded and followed by perceptual facilitation. The masking effects may be responsible for the alterations in the perception of a somaesthetic stimulus before and during movement of the stimulated area.
\end{abstract}

Perception of a mild electrical stimulus was reported by Coquery et al (1971) to be attenuated or obliterated when delivered several tens of milliseconds before a movement of the stimulated area. The hypotheses suggested for explaining this observation call for one of the two following mechanisms: A depression of perception might represent the inhibitory effect of the motor commands which have been shown to precede movement by approximately $100 \mathrm{msec}$. Alternatively, the decrease in perception could be due to a backward masking resulting from cutaneous and proprioceptive afferents elicited by displacement of the stimulated area.

The present investigation was carried out in order to assess the possibility of the latter hypothesis. Backward masking of the perception of an electrical stimulus was induced by a mechanical shock to the stimulated area, and its time course was measured. Forward masking was also studied because of its possible involvement in the abolition of perception during movement.

\section{METHOD}

Six members of the laboratory staff, between the ages of 22 and 34 , served as Ss in 161 -h experimental sessions. The first two sessions were used only for training and for determining a suitable range of stimulus intensities. Subsequently, forward and backward masking were tested, each during seven sessions.

Electrical stimuli, trains of three pulses with a frequency of $500 / \mathrm{sec}$, were applied to the tip of the middle finger. The cathode was a disk electrode, $8 \mathrm{~mm}$ in diam, containing electrode jelly and held on the ventral face of the fingertip by adhesive tape. The anode, a large tin plate covered with sponge cloth soaked with saline, was fastened to the wrist. Stimuli were delivered by a Grass stimulator through a stimulus isolation unit and a modified constant current unit. The modification in the constant current unit allowed the stimulus intensity to be incremented by precise steps of $50 \mu \mathrm{A}$. Skin impedance was always within the range of the regulation characteristics of the constant current unit.

The mechanical stimuli were applied $5 \mathrm{~mm}$ below the nail to the dorsal surface of the middle finger by an electromagnetic hammer with a circular head, $7 \mathrm{~mm}$ in diam. The head was placed $1.5 \mathrm{~mm}$ above the skin. Its total displacement was $3 \mathrm{~mm}$. With the coil driven above its rated voltage, the displacement, measured with a photocell, had a duration of $20 \mathrm{msec}$ (rise time:
$2 \mathrm{msec}$ ) in the absence of the finger. With the finger in place, its duration was reduced to $5 \mathrm{msec}$. The force of the mechanical slap was $2.9 \mathrm{~kg}$, as measured with a strain-gauge bridge. It was felt as a light, not painful, tap. The delay between the electrical command of the coil and the actual displacement of the hammer was measured and taken into account. In order to eliminate vibrations, the mechanical stimulator was mounted on a heavy frame separated from the table on which the S's hand rested.

White noise was provided at low volume through earphones for masking sounds from the instruments. Ss kept their eyes closed throughout the experiment.

Ss were seated with their right hands resting on a table. A click, loud enough to be heard in spite of the earphones, warned the Ss that they were going to be stimulated. A first electrical stimulus, used as a reference, was given $1 \frac{1 / 2}{\mathrm{sec}}$ after the warning signal. Three seconds later, the test stimulus was given, preceded or followed at variable intervals by the masking mechanical slap.

Intensity of stimulation was chosen in the following manner. Threshold for perception was first determined. Intensity was then increased until the stimulus reached a maximal level without being felt unpleasant. Intensity was then reduced by $0.25 \mathrm{~mA}$, and this was taken as the maximum stimulus. Thereafter, two other stimuli were chosen with such an intensity as to be reported equal to $25 \%$ and $50 \%$ of the maximum stimulus. During the first two sessions, the respective intensities of the stimuli were modified in order to be as close as possible to the expected ratios.

The nine possible pairs of reference and test stimuli were presented in a random order. The intervals between the test stimuli and the mechanical masking shocks were also randomized. In addition, pairs of electrical stimuli without any masking shock were given and used as controls.

Measure of the subjective intensities of the test stimuli was done. using a modification of the ratio scaling method devised by Ekman (1958): Ss had to express the intensity of the test and reference stimuli as a ratio, the stronger member of the pair always being rated 10 , whatever its objective intensity. After the experiment was completed, subjective values of the three stimuli, at different intervals before and after the masking shock, were expressed as a percent of the mean value of the strongest control stimulus measured in the seven sessions devoted to backward masking.

\section{RESULTS}

Both backward and forward masking were observed in all six Ss. Figure 1 gives the curves of two representative Ss for the three intensities of the test stimuli. 


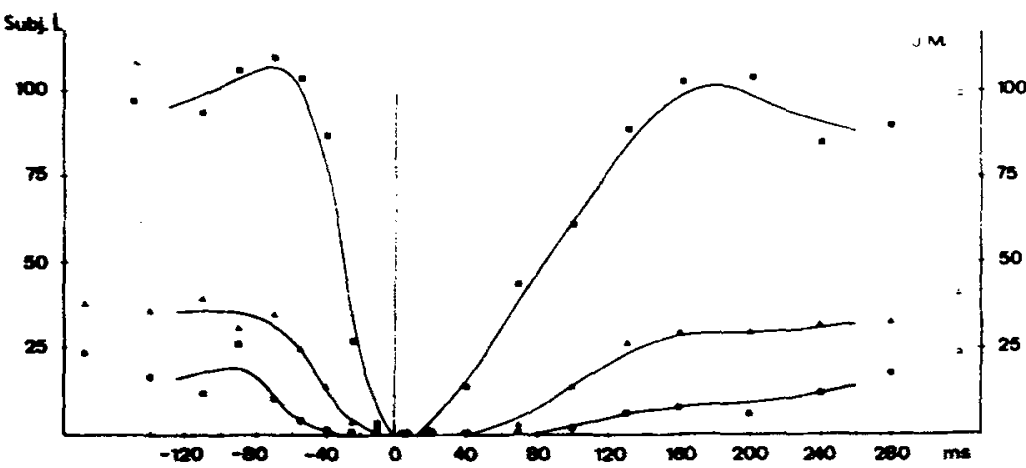

Fig. 1. Backward and forward masking effect for two Ss. Abscissa: Time interval in milliseconds between electrical test stimulus and mechanical masking shock. Onset of masking slap at time zero. Negative time values indicate that the electrical test stimulus precedes the mechanical slap (backward masking situation). Ordinates: Subjective intensities of the stimuli in percent of the control value of the strongest stimulus measured in the backward masking situation. Open symbols: control values. Filled symbols: test values. Each point is the mean of seven scale values, each obtained from three ratio judgments. Curves have been smoothed by using running averages over three consecutive values. Stimulus intensities were, respectively, $1.50,1.80$, and $2.45 \mathrm{~mA}$ for S J.M. For S M.C., they were $0.60,1.10$, and $2.15 \mathrm{~mA}$.

In order to compare durations of masking, we have taken as an index the time interval between the onset of the masking shock and the points at which the subjective intensity of a given stimulus falls to $50 \%$ of its control value. Duration of masking can thus be shown to be inversely related to stimulus intensity. This was true for five out of six Ss for the backward masking and for all Ss for the forward masking. For the six Ss, the median values of this index were 65,45 , and $25 \mathrm{msec}$ in the backward masking situation, and 145, 90 , and $55 \mathrm{msec}$ in the forward masking situation for test stimuli rated, respectively, 25, 48, and 100 (median values) on an arbitrary scale.

The same index shows that for all stimuli and for all Ss, the duration of forward masking is, on the average, 2.5 times longer than the duration of backward masking.

For the weakest stimuli, backward masking may extend over $100 \mathrm{msec}$; forward masking may still be observed beyond $250 \mathrm{msec}$.

There are some indications that the beginning and the end of the masking effects might be preceded or followed by an increase of the subjective intensities. This enhancement of perception was usually more apparent with the strongest test stimuli.

\section{DISCUSSION}

The method of subjective intensity scales adopted in this experiment has a distinct advantage over the threshold methods that were used in a majority of experiments by previous investigators. It allows a direct measurement of perception for stimulus intensities well above the perceptual threshold. In addition, this method makes it possible to observe any eventual perceptual facilitation effects.

The present results indicate a duration of backward masking much longer than has been so far reported. Using electrical shocks as test and masking stimuli, Schmid (1961) reports a very slight backward masking with a duration of less than $10 \mathrm{msec}$. Melzack et al (1963) indicate that a single mechanical slap on the forearm presented as long as $50 \mathrm{msec}$ before onset or after termination of an electrical shock on the same location increases the voltage needed to produce threshold and prick sensations. Our observations are in closer agreement with those of Abramsky et al (1971), who, using tactile pressure stimuli, observed backward masking with a duration of around $100 \mathrm{msec}$. However, these authors report that, in their experimental situation, backward masking is slightly larger than forward masking; our results show that, on the contrary, forward masking is always longer than backward masking.

The findings that both backward and forward masking are facilitated by decreasing the intensity of the test stimulus is also in agreement with the observations of Abramsky et al (1971).

The possibility of perceptual facilitation before and after the masking effects has not been reported so far for the somaesthetic modality. However. Schmid (1961) indicates that when a low-intensity conditioning (masking) stimulus is used, there is no masking effect but. instead, a slight facilitation is observed. It is possible that a weak conditioning stimulus might lead to the 
same facilitatory effects as a stronger conditioning stimulus delivered a long time before or after the test stimulus. It is interesting to note that a similar rebound has been observed in the visual system: Blanc-Garin (1969) notes an increase in the subjective intensity of a test stimulus when preceded at a long interval by a conditioning stimulus delivered in monocular or dichoptic conditions.

The results of the present experiment are compatible with the hypothesis that alterations in the perception of a cutaneous stimulus before and during a voluntary movement might be due to the backward, simultaneous, and forward masking effects exerted by afferents elicited by the displacement of the stimulated area.

\section{REFERENCES}

Abramsky, O., Carmon. A.. \& Benton, A. L. Masking of and by tactile pressure stimuli. Perception \& Psychophỵsics. 1971. $10,353-355$.

Blanc-Garin, J. Les relations temporelles dans le masquage latéral visuel. Année psỵchologique, 1966.66, 365-381.

Coquery, J.-M.. Malcuit. G.. \& Coulmance. M. Altérations de la perception d'un stimulus somesthésique durant un mouvement volontaire. Comptes-Rendus de la Société de Biologie, 1971. 1965, 1946-1951.

Ekman, G. Two generalized ratio scaling methods. Journal of Psychology, 1958, 45, 287-295.

Melzack, R., Wall, P. D., \& Weisz, A. Z. Masking and metacontrast phenomena in the skin sensory system. Experimental Neurology. 1963, 8. 35-46.

Schmid. E. Temporal aspects of cutaneous interaction with two-point electrical stimulation. Journal of Experimental Psychology, 1961, 61, 400-409.

(Received for publication July 21, 1972; revision received October 26,1972 .) 